\title{
Corals mass-cultured from eggs and transplanted as juveniles to their native, remote coral reef
}

\author{
R. Nakamura ${ }^{1, *}$, W. Ando ${ }^{1}$, H. Yamamoto ${ }^{2}$, M. Kitano ${ }^{2}$, A. Sato ${ }^{3}$, M. Nakamura ${ }^{3}$, \\ H. Kayanne ${ }^{4}$, M. Omori ${ }^{5}$ \\ ${ }^{1}$ Fisheries Infrastructure Development Center, 2-14-5 Tsukiji, Chuo-ku, Tokyo 104-0045, Japan \\ ${ }^{2}$ ECOH Corporation, 2-6-4 Kita-Ueno, Taito-ku, Tokyo 110-0014, Japan \\ ${ }^{3}$ Fisheries Infrastructure Department, Fisheries Agency, 1-2-1 Kasumigaseki, Chiyoda-ku, Tokyo 100-8907, Japan \\ ${ }^{4}$ Department of Earth and Planetary Science, University of Tokyo, 7-3-1 Hongo, Bunkyo-ku, Tokyo 113-0033, Japan \\ ${ }^{5}$ Akajima Marine Science Laboratory, 179 Aka, Zamami-son, Okinawa 901-3311, Japan
}

\begin{abstract}
We attempted to develop practical methods for coral reef rehabilitation, by means of the production of juveniles obtained from sexual reproduction, for a remote island where recruitment is limited. Adult corals (broodstocks) of Acropora tenuis were transported $1100 \mathrm{~km}$ from Okinotorishima, Japan's southernmost island in the Pacific, to a hatchery in Okinawa and maintained in land tanks. Eggs were obtained from captive spawning and the resulting larvae and juvenile corals were cultured under laboratory conditions. The present methodology enabled high survivorship and led to the successful mass production of coral juveniles. A total of 564 substrates with $\sim 63000$ juvenile corals at the age of 10 mo were transported to the native reef. They were then transplanted in 3 experimental treatments, in order to evaluate effectiveness of protection by cages and/or hiding the juveniles under other substrates. Additionally, the effects of orientation on coral growth were tested by attaching the juveniles face down. The cages effectively protected the corals from predation and nibbling by fishes. The unshaded, upward facing corals in the cages steadily increased their coverage nearly 4 -fold in $\sim 2$ yr.
\end{abstract}

KEY WORDS: Acropora $\cdot$ Sexual reproduction $\cdot$ Coral culture $\cdot$ Reef rehabilitation $\cdot$ Transplantation

\section{INTRODUCTION}

Coral reefs are renowned for their stunning biodiversity. They also contribute to local fishing and tourist industries and act as natural seawalls, protecting people from tsunami tidal waves and storm surge. Their recent worldwide decline is of serious concern, not only for scientists but also to the coastal communities that depend on coral reefs. Climate change and various local stresses from human activities are driving reefs to functional collapse. Of the world's coral reefs, $19 \%$ have already been lost with an additional $15 \%$ at risk of collapse within 10 to $20 \mathrm{yr}$ (Wilkinson 2008). Furthermore, one-third of all reef-building coral species may become endangered (Carpenter et al. 2008). Coral reef conservation should focus firstly on removing chronic stressors such as sedimentation, pollution, eutrophication and overfishing, to facilitate natural and long-term recovery. However, if the reduction of these stressors is not sufficient or in cases where extensive habitat and natural recruitment sources have been lost, effort must be taken toward reef rehabilitation through artificial improvement. This could be done via creation of coral habitats applying civil engineering, underwater silviculture and transplantation approaches (Fox \& Pet 2001, Omori \& Fujiwara 2004, Rinkevich 2005, Edwards \& Gomez 2007).

Rehabilitation of coral reefs has proven difficult, with results lagging in comparison to restoration of other ecosystems such as coastal wetlands and riparian habitats (e.g. Field 1996, for mangrove restora- 
tion). It is depressing to compare the small scale of active rehabilitation projects relative to the worldwide scale of coral reef degradation (Edwards \& Gomez 2007). There is an ongoing debate about the effectiveness and value of artificial coral reef rehabilitation. However, we believe that coral reef rehabilitation efforts should be pursued in the future. An encouraging example of the benefit of small-scale efforts is the fact that in Japan, $67 \%$ of the country is forested and $41 \%$ of the forest is artificially planted, an outcome of the people's continuous effort since $500 \mathrm{AD}$. A prime example is the forest surrounding the Meiji Shrine in Tokyo, which was created with 100000 trees consisting of 365 species planted nearly $90 \mathrm{yr}$ ago. We believe that, if we could facilitate local coral reef rehabilitation in key locations, it may result in a gradual increase in species diversity and composition over a time scale of years. This, in turn, could result in a cascading effect, as neighboring reefs will be provided with a new source of eggs and larvae (Omori 2011).

Past attempts to rehabilitate coral communities have mainly utilized transplanted coral fragments (Omori \& Okubo 2004, Shafir et al. 2006) due to its relative ease. However, use of fragments from a limited number of donor colonies may reduce genetic diversity. This is confounded by difficulties in sampling large numbers of coral fragments in areas where coral density is low.

Alternatively, coral juveniles can be produced by sexual reproduction within a laboratory setting (Hatta et al. 2004). This technique uses released eggs and sperm collected from broodstocks (some species are brooders) and can therefore increase genetic diversity in coral communities compared to asexual propagation. Colonies of Acropora tenuis that were transplanted as juveniles have grown to between 20 and $25 \mathrm{~cm}$ in diameter and began spawning $4 \mathrm{yr}$ after being cultured from eggs at Akajima Marine Science Laboratory (AMSL), Okinawa (Iwao et al. 2010).

The present research project was funded by the Japanese government in hopes of maintaining the status of Okinotorishima as an island with flourishing coral reefs, as well as increasing the habitat area for reef fishes. The goals were to develop a series of methods, based on findings from experiments conducted at AMSL (Omori 2005, Omori et al. 2008), with 3 objectives: (1) long-distance transportation and long-term maintenance of broodstock corals in land tanks located far from a remote location, (2) production of juvenile colonies from eggs in land tanks, and (3) transplantation of the cultured juvenile colonies back to the native, remote coral reef.

\section{MATERIALS AND METHODS}

\section{Study site}

Okinotorishima $\left(20^{\circ} 25^{\prime} \mathrm{N} 136^{\circ} 05^{\prime} \mathrm{E}\right)$, the southernmost island in Japan, located $1100 \mathrm{~km}$ southeast of Okinawa, was chosen as the target area (Fig. 1). It is a table reef, measuring $4.5 \mathrm{~km}$ east to west and $1.7 \mathrm{~km}$ north to south. Surface water temperature surrounding the island varied from 24.7 to $29.7^{\circ} \mathrm{C}$ (monthly averages) between May 2007 and April 2008. The underwater light intensity at $5 \mathrm{~m}$ depth around noon in fair weather was $\sim 1000 \mu \mathrm{mol} \mathrm{m} \mathrm{m}^{-2} \mathrm{~s}^{-1}$ in May 2007. Coral recruitment is extremely low at Okinotorishima caused by outflow of eggs and larvae from the reef as well as low recruitment from neighboring reefs. The average number of recruits on experimental settlement plates attached on the sea bottom was $14 \mathrm{~m}^{-2}$ at Okinotorishima in 2007 (our preliminary survey), whereas they were 1400 and $792 \mathrm{~m}^{-2}$ at Iriomote Island, Okinawa in 2005 and 2006, respectively (Nakamura \& Sakai 2010) and $4949 \mathrm{~m}^{-2}$ at Ishigaki Island, Okinawa in 2006 (Suzuki et al. 2008).

\section{Transportation and maintenance of broodstocks}

To acquire broodstocks for culturing juvenile corals, 14 colonies of the hermatypic coral Acropora tenuis, ranging 10 to $43 \mathrm{~cm}$ in diameter, were collected at a depth of 2 to $6 \mathrm{~m}$ in the reef flat of Okinotorishima in

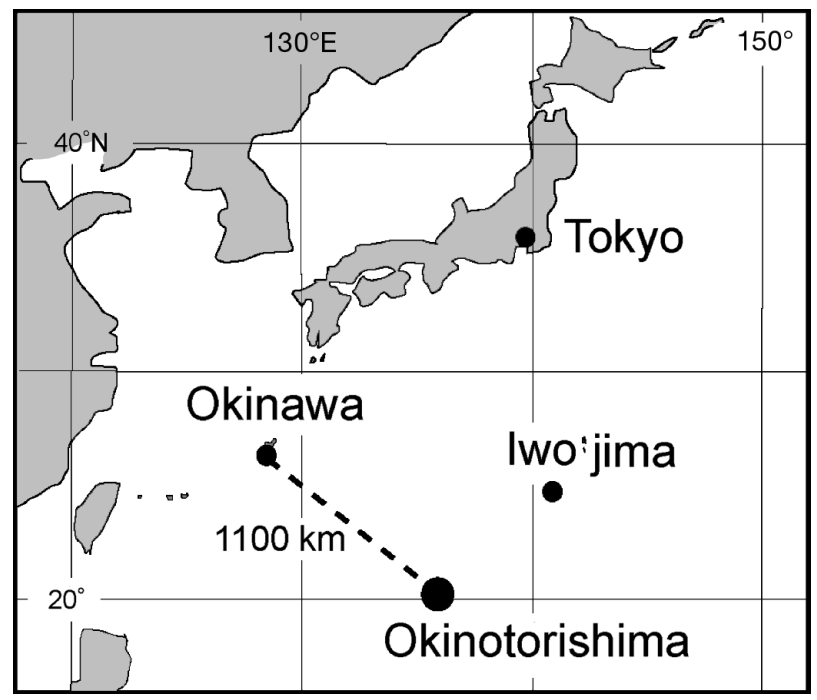

Fig. 1. Location of Okinotorishima. Okinotorishima is a solitary island formed by coral reefs in the Pacific Ocean, $1100 \mathrm{~km}$ from Japan 
August 2006 and May 2007. They were transported to the Akajima Coral Hatchery (ACH) on Akajima Island, Okinawa, $1100 \mathrm{~km}$ away, via a research vessel. During the cruise, the corals were kept on deck in rectangular fiberglass tanks with transparent acrylic lids. They were covered with $30 \%$ attenuation shade nets to limit light intensity and solar heating. One-third of the seawater in the tanks was exchanged with fresh seawater from the open sea 3 times a day. Water flow was created with submersible pumps in the tanks. Water temperature varied between 22.5 to $28.4^{\circ} \mathrm{C}$.

At the $\mathrm{ACH}$, the broodstock corals were maintained outdoors in rectangular fiberglass tanks $(2.4 \times$ $1.0 \times 0.9 \mathrm{~m}$ length $\times$ width $\times$ depth) or indoor in round transparent polycarbonate tanks (diameter $1.4 \mathrm{~m}$, depth $0.8 \mathrm{~m}$ ) with a transparent polycarbonate roof. Between June and November, $30 \%$ and $15 \%$ attenuation shade nets were used for outdoor and indoor tanks, respectively. The underwater light intensity was measured ( 1 measurement for $1 \mathrm{~s}$ every $15 \mathrm{~s}$, averaged over $3 \mathrm{~min}$ ) using a quantum sensor (LI-192, Li-Cor) connected to a data logger (LI-1400, Li-Cor) around noon on a sunny day every 1 to 2 mo between March and December 2008. In both types of the tanks, the light intensity varied from 622 to $1566 \mu \mathrm{mol} \mathrm{m}{ }^{-2} \mathrm{~s}^{-1}$. The tanks had flow-through seawater with an exchange rate of half a tank volume $\mathrm{h}^{-1}$. The water current velocity was maintained at $\sim 10 \mathrm{~cm} \mathrm{~s}^{-1}$ by means of aeration. The monthly average water temperature in the tanks ranged from 21.8 to $29.0^{\circ} \mathrm{C}$ between August 2006 and April 2008 .

\section{Production of coral colonies}

The laboratory corals spawned in June 2007. The following methods of fertilization and larval rearing in Hatta et al. (2004) were adopted: for fertilization, the sperm concentration was set at $10^{7} \mathrm{ml}^{-1}$; after fertilization and rinsing with fresh seawater, the embryos were reared in various polycarbonate tanks of 30 to $500 \mathrm{l}$ at a concentration of 100 to $300 \mathrm{ind} . \mathrm{l}^{-1}$; during this period, three-quarters of the water in each tank was exchanged with fresh seawater once a day.

For settlement, planula larvae were equally distributed to 4 rectangular tanks $(1.7 \times 0.8 \times 0.4 \mathrm{~m}$ length $\times$ width $\times$ depth) $5 \mathrm{~d}$ post-fertilization. Unglazed ceramic substrates (riverbed rehabilitation tiles, $12 \times 12 \times$ $2.5 \mathrm{~cm}$ length $\times$ width $\times$ depth, Seto Ceramic Research Center) were used for settlement, with 5 rows of $1.5 \times 1.5 \mathrm{~cm}$ square holes bored along the length and breadth of each tile (Fig. 2). In each settlement tank, 160 tiles were placed in stacks of 2 on the bottom. Hatta et al. (2004) described that more larvae settled on substrates which had been placed in the seawater beforehand to grow some other biota on the surface than on those without such pre-processing. In this study, 640 substrates had been submerged for the previous $4 \mathrm{mo}$ at a depth of $4 \mathrm{~m}$ in Aka Fishing Port, Akajima Island. Some pieces of the substrates (20 pieces) cracked during the submergence were replaced with the same types of substrates submerged for 16 mo for the larval settlement. During the settlement period ( 4 and $5 \mathrm{~d}$ for the cohorts of June 8 and 9, respectively), half the tank water was exchanged daily with fresh seawater.

The substrates with juvenile colonies were then transferred to 6 outdoor raceway tanks $(5.2 \times 0.8 \times$ $0.4 \mathrm{~m}$ length $\times$ width $\times$ depth). The number of juveniles on the substrates was estimated by enumeration of 13 randomly chosen substrates from each upper and lower tile group (upper and lower refer to the position in the settlement substrate setup).

The raceway tanks had aerated, flow-through seawater at an exchange rate of half the tank volume $\mathrm{h}^{-1}$. The average monthly seawater temperature in the tanks during the rearing period from June 2007 to April 2008 varied between 20.9 and $29.0^{\circ} \mathrm{C}$. From June to November, $30 \%$ attenuation shade nets were used to control the light intensity in the tank, whereas in other months the tanks were covered with transparent vinyl tents ( $20 \%$ attenuation). The underwater light intensity varied between 554 and $1059 \mu \mathrm{mol} \mathrm{m} \mathrm{m}^{-2} \mathrm{~s}^{-1}$ (measured as described in 'Transportation and maintenance of broodstocks' above).

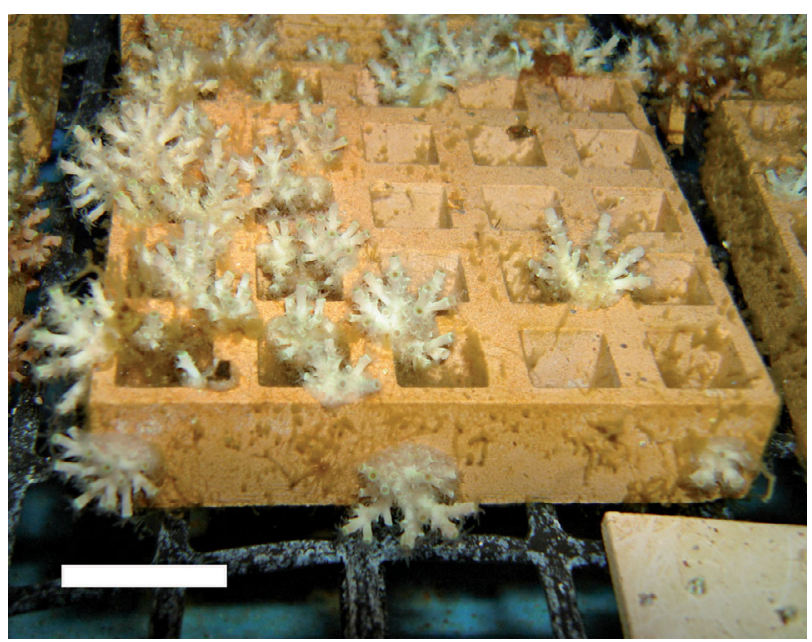

Fig. 2. Acropora tenuis. Larval settlement substrates with 10-mo-old juveniles immediately before transportation to Okinotorishima. Scale bar: $2 \mathrm{~cm}$ 
To control the macroalgae that might compete with the juvenile corals for space, herbivorous snails such as juvenile Trochus niloticus and adult Lunella granulata were added to the tanks. Young fish such as the rabbitfish Siganus spinus, the surgeonfish Acanthurus triostegus and the butterflyfish Chaetodon kleinii were also introduced into the tanks to remove macroalgae and sea anemones. Some algae that were not grazed by those animals had to be removed by hand once a month.

Survival and growth of 116 juveniles on 5 substrates taken from various tanks were monitored. To avoid fusion of juvenile colonies, substrates with comparably fewer juvenile corals were chosen for monitoring.

\section{Transplantation}

The transportation of juvenile corals to Okinotorishima for transplantation was carried out in April 2008, with the same method as used for the broodstock corals. Seawater temperature in tanks with the juveniles gradually rose from $22.5^{\circ} \mathrm{C}$ to $29.0^{\circ} \mathrm{C}$.

On the basis of the findings from our preliminary field surveys in 2006 and 2007, sites with suitable environmental conditions but relatively few corals were chosen for transplantation. The substrates with the juveniles were attached to convex surfaces of knolls at least $50 \mathrm{~cm}$ or more above the sea floor, using steel rods and epoxy cement (S-dine Joiner W, Sekisui Fuller) (Fig. 3). The growth (coverage) of the juvenile corals on the substrates was compared among the following 3 types of substrate fixation methods (Fig. 4): (1) two substrates were fixed $1 \mathrm{~cm}$ apart on a rod with corals on its top and protected by vinyl-coated wire cages with a mesh size of $\sim 5 \mathrm{~cm}$ (Treatment A); (2) two substrates were fixed to a rod, similar to the method described above, but without the cages (Treatment B); (3) two substrates were fixed $3 \mathrm{~cm}$ apart on a rod, with the juveniles facing each other and no cages for protection (Treatment C). Among the 282 pairs of substrates fastened on the knolls, 108 pairs that had comparably fewer colonies were chosen and allocated randomly for this experiment; 43 pairs received Treatment A, 33 received Treatment $B$, and 32 received Treatment $C$. Additionally, to determine if location affected coral survivability, the pairs in each experimental treatment were attached on the knolls at the 4 points of the compass and at 3 heights from the sea bottom $(50,100$, and $150 \mathrm{~cm})$. Monitoring surveys were carried out 8, 10, and 22 mo after the transplantation, measuring coverage of live corals to the top surface area $(12 \times 12 \mathrm{~cm})$ of all the experimental substrates at the site, using a small $10 \times$ $10 \mathrm{~cm}$ quadrat.

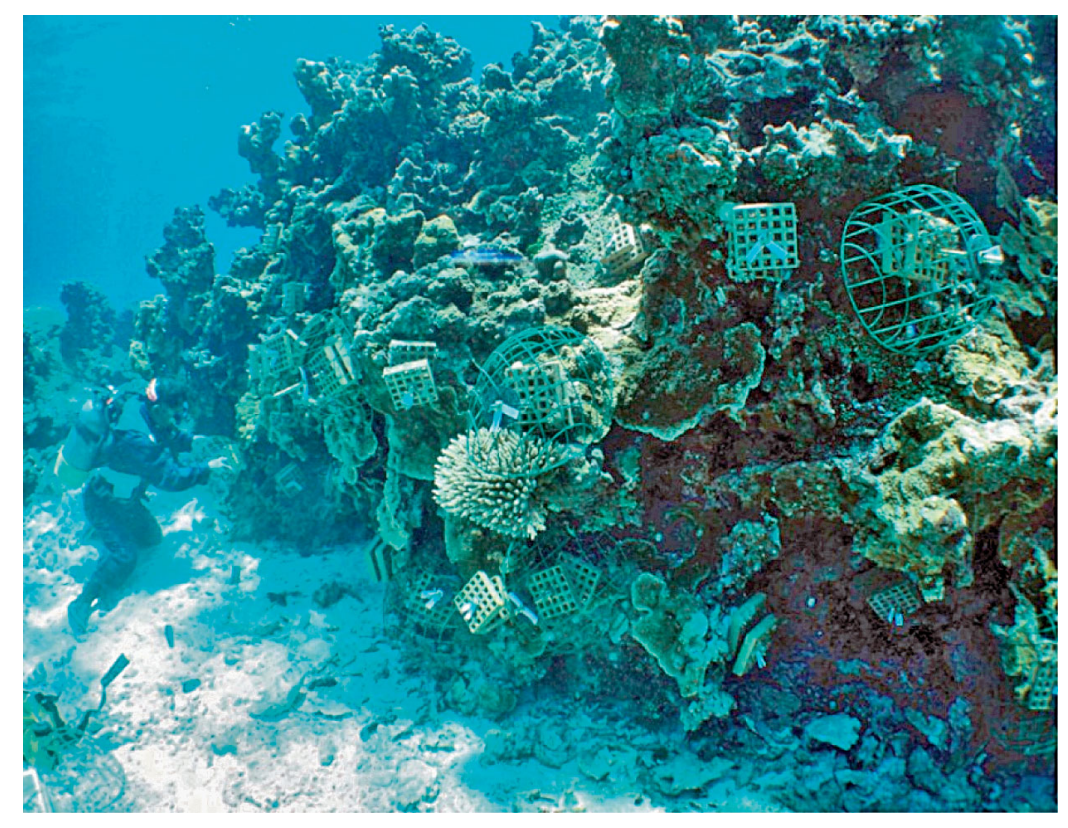

Fig. 3. Acropora tenuis. Transplanted juvenile corals at Okinotorishima. Substrates with juvenile corals were fixed to the knolls ( $\sim 5 \mathrm{~m}$ high) with steel rods and epoxy cement at a depth of $\sim 6 \mathrm{~m}$ (at low tide)
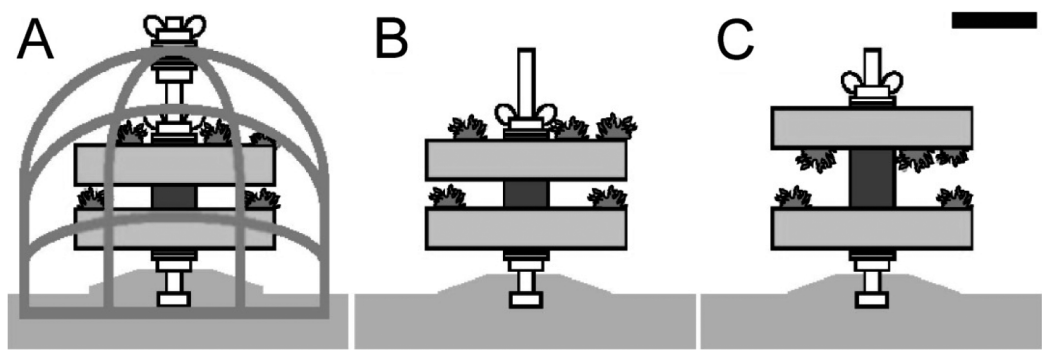

Fig. 4. Acropora tenuis. Examination of growth and survivorship of the juvenile corals using 3 types of transplantation methods. (A) Treatment A: substrates covered by a protection cage. $(B, C)$ Treatments B and C: substrates without the protection cage. The corals on upper and lower substrates face upward in A and B, but face each other in C. Scale bar: $5 \mathrm{~cm}$ 
Table 1. Acropora tenuis. Results of juvenile production and rearing. Percent survivorship after fertilization in parentheses. The larvae of both spawning dates (in 2007) were stocked in the same tanks for settlement (na: not applicable)

\begin{tabular}{|lcccc|}
\hline $\begin{array}{l}\text { Spawning } \\
\text { date }\end{array}$ & Fertilized eggs & Larvae & Settled larvae & $\begin{array}{c}\text { Juveniles } \\
(10 \text {-mo-old })\end{array}$ \\
\hline $\begin{array}{l}\text { June } 8 \\
\text { June } 9\end{array}$ & $11995(100)$ & $6666(55.6)$ & na & na \\
Total & $224873(100)$ & $198216(88.1)$ & na & na \\
& $236868(100)$ & $204882(86.5)$ & $110848(46.8)$ & $65622(27.7)$ \\
\hline
\end{tabular}

\section{RESULTS}

All 14 broodstock colonies were in good condition when transported to the $\mathrm{ACH}$, and 11 surviving colonies were brought back to the native reefs in April 2008.

Mass spawning in 8 out of 11 broodstocks occurred on June 8 and 9, 2007. The spawning dates in the tanks were not synchronized with mass spawning of local corals in the waters around Akajima. A total of 237000 eggs were used for production of juvenile colonies (Table 1). Fertilization was successful in 98 and $93 \%$ of eggs spawned on June 8 and 9, respectively. Approximately 111000 (54\%) of 205000 larvae settled onto the substrates (Table 1). The average number of juveniles on a substrate was $173.2 \pm 152.6$ (mean $\pm \mathrm{SD}$ ).

Survivorship was slightly lower from 6 to $10 \mathrm{mo}$ after settlement (December-April; Fig. 5), most likely due to lower water temperatures (monthly averages

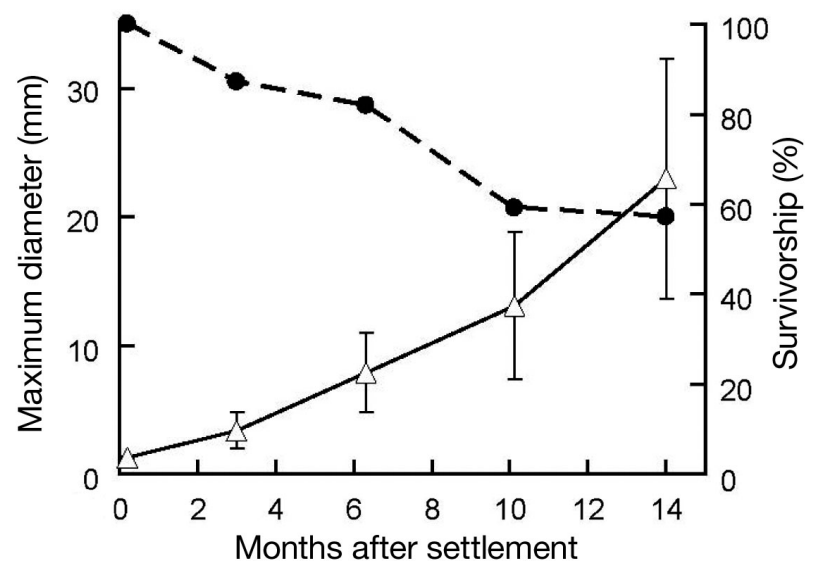

Fig. 5. Acropora tenuis. Growth and survival of juvenile Acropora tenuis after settlement in the tanks in June 2007. Solid line: mean $( \pm \mathrm{SD})$ maximum diameter $(\mathrm{N}=50)$; broken line: survivorship (initial no. of juvenile corals $=116$ ). Data from the 14th month after settlement were obtained from juveniles that remained in tanks of the Akajima Coral Hatchery without transplantation ranged between 20.9 and $22.0^{\circ} \mathrm{C}$ ). Growth rate (measured as the longest diameter of the colonies) was less during winter than in other seasons (December-April: $0.047 \mathrm{~mm} \mathrm{~d}^{-1} \mathrm{vs}$. April-August: $0.084 \mathrm{~mm} \mathrm{~d}^{-1}$ ). It was estimated that $\sim 66000$ juveniles ( $59 \%$ of settled corals) survived until April 2008 (10 mo after settlement; Fig. 5). The overall mean maximum diameter was $13.1 \pm 5.7 \mathrm{~mm}$ (mean $\pm \mathrm{SD})$.

On April 22, 2008, 10 mo after larval settlement, 564 substrates with $\sim 63000$ juvenile corals of Acropora tenuis were transported from $\mathrm{ACH}$ via research vessel and arrived $60 \mathrm{~h}$ later in Okinotorishima. There were no mortalities of the juveniles during transportation.

Results of the 3 transplantation treatments were as follows: a consistent and significant increase in coral coverage was recorded only on the unshaded corals (upper substrate) within cages of Treatment A, which provided protection from predation or nibbling by fishes. The coverage increased approximately 4 -fold during the monitoring period (2-way ANOVA, $F=$ 18.05, $\mathrm{df}=5,210, \mathrm{p}<0.01$; Tukey HSD test, $\mathrm{p}<0.01$; Fig. 6). The shaded corals (lower substrate) in Treatment A and all corals in Treatments B and C showed a similar tendency in terms of coverage; the coverage decreased for 8 to $10 \mathrm{mo}$ after transplantation and then increased gradually. During our survey in May 2009, the filefish Cantherhines dumerilii and the puffer Arothron meleagris were observed nibbling

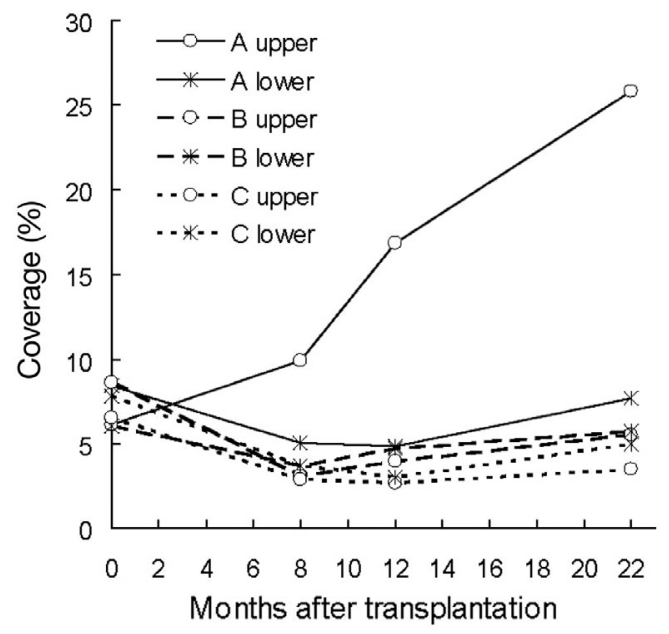

Fig. 6. Acropora tenuis. Change in mean coverage of juvenile corals on the substrates after transplantation. A, B, and C refer to Treatments A, B, and C, respectively. The labels 'upper' and 'lower' indicate upper and lower substrates, respectively (see Fig. 4) 
on the transplanted corals. However, it occurred that the coral branches, although damaged by predatory fishes, became thicker (data not shown).

On the other hand, there was no significant difference in coral coverage among the 4 points of the compass (2-way ANOVA, $F=0.96$, df $=3,212$, p > 0.1) as well as among the 3 height levels (2-way ANOVA, $F=0.28$, df $=2,213$, p > 0.1).

\section{DISCUSSION}

We were successful in mass culturing coral from eggs in land tanks and transplanting 63000 juveniles on 564 substrates back to the native reef, $1100 \mathrm{~km}$ away. Transplantation of the juvenile corals has been previously attempted, but with limited numbers of colonies. For instance, Omori et al. (2008) transplanted 2000 juvenile colonies, which were cultured from eggs using nursery cages suspended in the sea. We achieved the present results by optimizing each step of the mass culture process, from longterm rearing of broodstocks to transplantation of the juvenile colonies.

We found that for maintaining the corals in tanks as broodstock, light and water current were 2 very important factors that should be regulated and maintained at optimum conditions along with seawater temperature. The median light intensity in the tanks was approximately the same as that at Okinotorishima. Recent studies indicate that water flow is important for growth and recovery of some corals after bleaching, as low flow reduces mass transfer of gases and molecules, leading to the dysfunction of the algae-coral symbiosis (Nakamura et al. 2003, 2005, Nakamura \& Yamasaki 2005). For maximizing fitness of broodstock corals, it would be necessary to regulate water motion and flow in tanks similar to the habitat conditions of the target species.

The production of juvenile corals in land tanks is laborious compared with that in ocean nurseries. However, frequent maintenance of the tanks results in higher survivorship of the juveniles; survivorship of 1-yr-old juvenile colonies after settlement was 1 to $3 \%$ in ocean cage nurseries (Omori 2008), whereas the average survivorship of 10-mo-old juveniles after settlement was $59 \%$ in the present study.

Furthermore, we succeeded in transporting the broodstock and juveniles over a long distance. This technique is particularly useful for rehabilitation of coral reefs at remote locations such as Okinotorishima, where it is impractical to have a hatchery and nursery for production and rearing of juveniles. The success of our transport and mass-culture techniques leads the way for rehabilitation of coral reefs by establishing a coral hatchery and nursery in a location far away from the reef.

Regrettably, due to the limited period of calm seas around Okinotorishima, we were forced to transport small, 10-mo-old colonies ( 13 $\mathrm{mm}$ in diameter) for transplantation. They were much smaller than 4 to $6 \mathrm{~cm}$, which is considered to be the optimum colony size of Acropora for transplantation (Soong \& Chen 2003, M. Omori pers. comm.). Additionally, the large and rather complicated structure of the substrates used in the present experiment resulted in too many juveniles on one substrate while only a few wellgrown colonies are needed per substrate for transplantation.

Due to the lack of sufficient data, we were unable to conclude on the reduced growth of the shaded and/or downward facing juvenile corals after transplantation. We wish to address the factors that may have led to this phenomenon in a future study.

Estimate costs of the nursery culture of coral fragments suggest that US\$0.5 to $\$ 1.0$ are needed to propagate 1 juvenile (Shafir et al. 2006). AMSL's methods of culturing corals by means of sexual reproduction are more expensive; the price of one 1.5-yrold juvenile coral (ca. $6 \mathrm{~cm}$ in diameter) is US\$10 (M. Omori pers. comm.). In the present study, the total expenditure for producing $\sim 66000,10$-mo-old juvenile corals was $\sim 7.96$ million Japanese yen ( US\$98 000). This figure excludes the initial costs of the hatchery and rearing facilities as well as transport costs of broodstocks and juveniles, but includes personnel expenses, cost of running the facilities, and cost of daily expendables. Thus, the cost of a juvenile coral was $\sim 120$ JPN yen ( US\$1.5). As a result, the cost of one substrate with a surplus of juvenile corals produced in the present study was $\sim 13400$ JPN yen ( US\$163). Details of the costs are listed in Table 2. Costs for collection of broodstock colonies and transplantation of the juvenile corals to the reef were considerably higher, indicating that reef rehabilitation efforts at remote reef sites require substantial financial investment.

Nevertheless, the success of the present study paves the way for large-scale rehabilitation of coral reefs. The expenses should be properly managed to offset the costs of rehabilitation by the economical and ecological gains. For instance, if smaller, novel substrates such as the 'coral peg' (Omori \& Iwao 2009) were used, we could produce tens of thousands of substrates with 2 or 3 large juvenile corals, which are more suitable for transplantation. Transferring 
Table 2. Expenditures for production of $\sim 66000,10$-mo-old juvenile corals as well as collection of broodstocks and transplantation of juveniles. Currency: JPN Yen ( 81 JPN Yen $=$ 1 US\$, as of March 26, 2011)

\begin{tabular}{lr}
\hline Items of expenditure & Cost \\
\hline $\begin{array}{l}\text { Depreciation and lease of equipment } \\
\text { (on 3 yr depreciation period) }\end{array}$ & 955000 \\
$\begin{array}{l}\text { Consumption articles } \\
\text { Charge for repair and specialized } \\
\text { maintenance service of equipment }\end{array}$ & 228000 \\
$\begin{array}{l}\text { Electricity, water and fuel } \\
\text { Personnel expenses incl. maintenance } \\
\text { of juveniles ( 230 man-days) }\end{array}$ & 194000 \\
$\begin{array}{l}\text { Others (communication expenses, } \\
\text { insurance, water quality check) }\end{array}$ & 725000 \\
$\begin{array}{l}\text { Subtotal for seed production } \\
\text { Collection and transportation of broodstocks } \\
\text { (a vessel of 500 t and 3 researchers for } 7 \text { d) }\end{array}$ & 12600000 \\
$\begin{array}{l}\text { Transportation and transplantation of } \\
\text { juvenile corals (a vessel of 500 t and } \\
5 \text { researches for 15 d) }\end{array}$ & 30000000 \\
Total & 151000 \\
\hline
\end{tabular}

the juvenile corals from land tanks to an ocean cage nursery, once they have developed into a colony size capable of survival, could reduce the cost of cultivation.

While rehabilitation of degraded coral reefs was not attempted until the 1980s, silviculture on land has a long history of over $1600 \mathrm{yr}$. We must learn more from ecological studies on restoration of terrestrial habitats. There is still no guarantee that degraded reef ecosystems will resume their original function through the techniques of coral reef rehabilitation currently available. The present transplantation experiment was carried out at an oceanic atoll, where only natural factors, such as strong wave action and shortage of coral recruits, limit the propagation of corals. Various anthropogenic factors, such as eutrophication and soil or wastewater runoff, which negatively affect coral reef communities, are nonexistent. Therefore, we are planning a similar experiment in reefs degraded by anthropogenic disturbances in Okinawa.

Acknowledgements. We are grateful to T. Hayashibara, N. Ishioka, K. Iwao, S. Kakuma, N. Mikami, A. Nakayama, and $\mathrm{K}$. Watanabe, for helpful discussion and technical advice on rearing, juvenile production and transplantation of corals, and to T. Aota and A. Watanuki for technical assistance. We thank D. M. Checkley, Jr., L. A. Levin, and A. Ohdera for help with proofreading the manuscript. This study was carried out as part of a coral propagation project by Fisheries Agency, Japan.

\section{LITERATURE CITED}

Carpenter KE, Abrar M, Aeby G, Aronson RB and others (2008) One-third of reef-building corals face elevated extinction risk from climate change and local impacts. Science 321:560-563

Edwards AJ, Gomez ED (eds) (2007) Reef restoration concepts and guidelines: making sensible management choices in the face of uncertainty. Coral Reef Targeted Research \& Capacity Building for Management Programme, St Lucia

Field C (ed) (1996) Restoration of mangrove ecosystems. International Society for Mangrove Ecosystems, Okinawa

Fox HE, Pet JS (2001) Pilot study suggests viable options for reef restoration in Komodo National Park. Coral Reefs 20: 219-220

Hatta M, Iwao K, Taniguchi H, Omori M (2004) Seed production. In: Omori M, Fujiwara S (eds) Manual for restoration and remediation of coral reefs. Nature Conservation Bureau, Ministry of the Environment, Japan, p 14-28

Iwao $\mathrm{K}$, Omori $\mathrm{M}$, Taniguchi $\mathrm{H}$, Tamura M (2010) Transplanted Acropora tenuis (Dana) spawned first in their life 4 years after culture from eggs. Galaxea, J Coral Reef Stud 12:47

> Nakamura M, Sakai K (2010) Spatiotemporal variability in recruitment around Iriomote Island, Ryukyu Archipelago, Japan: implications for dispersal of spawning corals. Mar Biol 157:801-810

Nakamura T, Yamasaki H (2005) Requirement of water-flow for sustainable growth of Pocilloporid corals during high temperature periods. Mar Pollut Bull 50:1115-1120

Nakamura T, Yamasaki H, van Woesik R (2003) Water flow facilitates recovery from bleaching in the coral Stylophora pistillata. Mar Ecol Prog Ser 256:287-291

Nakamura T, van Woesik R, Yamasaki H (2005) Photoinhibition of photosynthesis is reduced by water flow in the reef-building coral Acropora digitifera. Mar Ecol Prog Ser 301:109-118

Omori M (2005) Success of mass culture of Acropora corals from egg to colony in open water. Coral Reefs 24:563

Omori M (2008) Coral reefs at risk: the role of Japanese science and technology for restoration. In: Leewis RJ, Janes $M$ (eds) Advances in coral husbandry in public aquariums. Public aquarium husbandry series Vol 2, Burger's Zoo, Arnhem, p 401-406

> Omori M (2011) Degradation and restoration of coral reefs: experience in Okinawa, Japan. Mar Biol Res 7:3-12

Omori M, Fujiwara S (eds) (2004) Manual for restoration and remediation of coral reefs. Nature Conservation Bureau, Ministry of the Environment, Japan

Omori M, Iwao K (2009) A novel substrate (the 'coral peg') for deploying sexually propagated corals for reef restoration. Galaxea, J Coral Reef Stud 11:39

Omori M, Okubo N (2004) Previous research and undertaking of coral reefs restoration. In: Omori M, Fujiwara S (eds) Manual for restoration and remediation of coral reefs. Nature Conservation Bureau, Ministry of the Environment, Japan, p 3-13

Omori M, Iwao K, Tamura M (2008) Growth of transplanted Acropora tenuis 2 years after egg culture. Coral Reefs 27: 165

Rinkevich B (2005) Conservation of coral reefs through active restoration measures: recent approaches and last decade progress. Environ Sci Technol 39:4333-4342

- Shafir S, Rijn JV, Rinkevich B (2006) Steps in the construc- 
tion of underwater coral nursery, an essential component in reef restoration acts. Mar Biol 149:679-687

Soong K, Chen T (2003) Coral transplantation: regeneration and growth of Acropora fragments in a nursery. Restor Ecol 11:62-71

Suzuki G, Hayashibara T, Shirayama Y, Fukami H (2008)

Editorial responsibility: Matthias Seaman,

Oldendorf/Luhe, Germany
Evidence of species-specific habitat selectivity of Acropora corals based on identification of new recruits by two molecular markers. Mar Ecol Prog Ser 355:149-159

Wilkinson C (ed) (2008) Status of coral reefs of the world: 2008. Global Coral Reef Monitoring Network and Reef and Rainforest Centre, Townsville

Submitted: September 8, 2010; Accepted: June 14, 2011

Proofs received from author(s): August 21, 2011 